\title{
Depression after low-energy fracture in older women predicts future falls: a prospective observational study
}

\author{
Martha van den Berg ${ }^{1 *}$, Noortje A Verdijk2 ${ }^{2}$ Geraline L Leusink ${ }^{3}$, Colette JM Wijnands-van Gent ${ }^{4}$, \\ Arnold C Romeijnders ${ }^{4}$, Victor JM Pop ${ }^{1}$ and Joop PW van den Bergh ${ }^{5,6}$
}

\begin{abstract}
Background: Falls are one of the main causes of fractures in elderly people and after a recent fracture, the risk of another fall is increased, resulting in subsequent fracture. Therefore, risk factors for future falls should be determined. We prospectively investigated the relationship between depression and the incidence of falls in postmenopausal women after a low-energy fracture.

Methods: At baseline, 181 women aged 60 years and older who presented with a recent low-energy fracture were evaluated at the fracture and osteoporosis outpatient clinics of two hospitals. As well as clinical evaluation and bone mineral density tests, the presence of depression (measured using the Edinburgh Depression Scale, EDS, depression cut-off > 11) and risk factors for falling were assessed. During two years of follow-up, the incidence of falls was registered annually by means of detailed questionnaires and interviews.

Results: Seventy-nine (44\%) of the women sustained at least one fall during follow-up. Of these, $28 \%(n=22)$ suffered from depression at baseline compared to $10 \%(n=10)$ of the 102 women who did not sustain a fall during follow-up $\left(X^{2}=8.76, \mathrm{df}=1, p=.003\right)$. Multiple logistic regression showed that the presence of depression and co-morbidity at baseline were independently related to falls $(\mathrm{OR}=4.13,95 \% \mathrm{Cl}=1.58-10.80 ; \mathrm{OR}=2.25,95 \% \mathrm{Cl}$ $=1.11-4.56$, respectively) during follow-up.

Conclusions: The presence of depression in women aged 60 years and older with recent low-energy fractures is an important risk factor for future falls. We propose that clinicians treating patients with recent low-energy fractures should anticipate not only on skeletal-related risk factors for fractures, but also on fall-related risk factors including depression.
\end{abstract}

\section{Background}

Falls are a major problem in older adults. The incidence increases with age and is higher in women than in men $[1,2]$. Furthermore, falls are among the main causes of diminished functioning and hospitalisation $[3,4]$. In 2002, it was estimated that, worldwide, 391,000 people of all ages died of injury-related falls in that year [5]. The costs of non-fatal fall injuries among adults over 64 years of age in the US were estimated at \$19 billion in 2000 [6].

\footnotetext{
* Correspondence: m.caers@pozob.nl

${ }^{1}$ Tilburg University, CoRPS - Center of Research on Psychology in Somatic

diseases, PO Box 90153, 5000 LE Tilburg, the Netherlands

Full list of author information is available at the end of the article
}

Up to $70 \%$ of low-energy fractures (defined as resulting from a fall from standing height or lower) are caused by falls $[7,8]$. Furthermore, it has been shown that $19 \%$ of women with a recent low-energy fracture reported another fall within three months of that fracture [9]. Falls are a strong and independent risk factor for fractures in elderly people [10]. Therefore, after age and bone mineral density (BMD), the number of falls during the past 12 months was included in the recently developed Garvan nomogram that can be used for the calculation of absolute five- and 10-year fracture risk $[11,12]$. For the prevention of fractures, attention should not only be focussed on the prevention and treatment of low BMD, but also on the prevention of falls.

\section{() Biomed Central}


Several risk factors for falls in older people have been studied. In a recent systematic review, a total of 31 risk factors were distinguished, assessed by at least five studies [1]. Of these, age, female sex, a history of falls, comorbidity and the use of medication were among the factors most frequently studied, and which had the greatest impact on future falls. Moreover, depression was found to have a negative effect on falls [1].

Depression (high depressive symptom scores as well as syndromic depression) has been described as a potential risk factor for falls in various samples and settings [13-16]. The prevalence of high depressive symptom scores in elderly Dutch women has been estimated to be $17 \%$ [17]. In Dutch primary care, $19 \%$ of women aged over 55 years suffer from high depressive symptomatology [18]. Furthermore, it has been shown that depressed patients suffer from poorer recovery after fracture $[19,20]$.

To the best of our knowledge, the relationship between depression and falls in patients with a history of recent low-energy fracture has not yet been studied. Therefore, the current study investigated the occurrence of depression and falls during a two-year follow-up period in post-menopausal women with a recent lowenergy fracture.

\section{Methods}

\section{Subjects}

The current study was part of a larger project on the development of an osteoporosis care management programme in primary care [21]. Between October 2006 and July 2008, primary care patients who visited the fracture and osteoporosis (F\&O) outpatient clinics of two hospitals in the south-east of the Netherlands after suffering from low-energy fracture, were informed about the project. During the period of inclusion, 738 patients aged 50 years and older who visited the F\&O outpatient clinics, were interested in participating (Figure 1). After primary fracture care, all patients were invited to undergo BMD measurement and further clinical evaluation by a specialised nurse.

Patients with insufficient knowledge of the Dutch language $(n=6)$, inadequate cognitive abilities (i.e., predementia, $n=12$ ), or a fracture that had occurred more than three months previously $(n=115)$, were excluded for the current study. Moreover, all men as well as women younger than 60 years of age were also excluded. A total of 362 women were eligible for participation. Ultimately, 314 women $(87 \%)$ provided written informed consent and 208 completed the two-year follow-up (Figure 1).

At baseline, as well as regular F\&O assessment, all the patients completed a set of standardised questionnaires for the assessment of depressive symptoms and the presence of risk factors for falling. During follow-up, the incidence

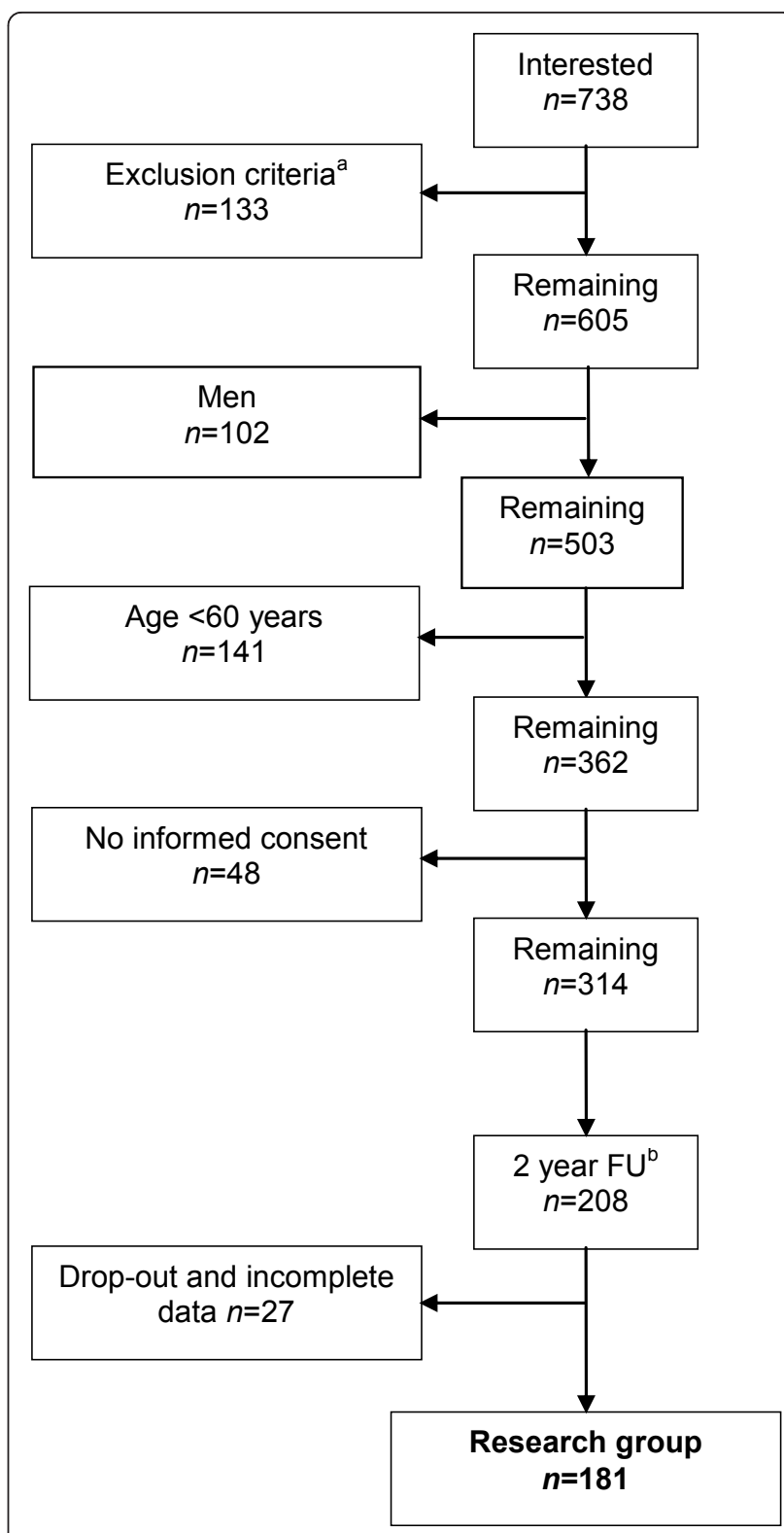

Figure 1 Flowchart of participants included in the current twoyear follow-up study. ${ }^{a}$ Insufficient knowledge of the Dutch language $n=6$, inadequate cognitive abilities $n=12$, history of fracture $>3$ months earlier $n=115 .^{b} \mathrm{FU}=$ Follow-up

of falling was registered annually by means of detailed questionnaires and interviews. Since 27 of the women returned incomplete questionnaires, the final sample for data analysis includes 181 women. All women were advised to use adequate calcium and vitamin D supplementation. Women with osteoporosis were referred to their general practitioner for treatment with anti-osteoporosis medication. The study was approved by the medical ethical committee of the Máxima Medical Centre Veldhoven, the Netherlands, and was carried out in accordance with the Declaration of Helsinki. 


\section{Measurements}

\section{Demographic and fracture characteristics}

Demographic characteristics (age, marital status and education level) were collected using self-report forms (Table 1). The demographic characteristics of the women participating in this study were similar to those of the total female population visiting the F\&O clinics (data not shown). Information regarding fracture type was provided by the F\&O clinics, and was classified according to Center et al. [22] into hip fractures, major fractures (vertebra, pelvis, distal femur, proximal tibia, multiple rib, and proximal humerus), minor fractures (all remaining osteoporotic fractures, excluded fingers and toes), and finger and toe fractures.

\section{Bone Mineral Density}

BMD was measured using a Hologic W Dual energy Xray Absorptiometry (DXA) system. In accordance with the World Health Organization (WHO) classification, osteoporosis was defined as a T-score $\leq-2.5 \mathrm{SD}$ in the spine and/or femoral neck, osteopenia as a T-score $<-1.0$ and $>-2.5 \mathrm{SD}$, and normal BMD as a T-score $\geq-1.0$ [23]. Risk factors for falling

Risk factors for falling were determined at baseline in accordance with the Dutch guidelines 'Prevention of fall incidents in the elderly' [24,25]. These guidelines were developed in 2004 by the Dutch Institute for Healthcare Improvement $[24,25]$. The following characteristics were assessed at baseline: age, living on one's own, $\geq 1$ falls during the 12 months prior to inclusion, use of a walking aid, use of anti-depressants, use of sedatives, use of antihypertensives, $\geq 2$ units of daily alcohol consumption, and physical inactivity. The existence of co-morbidity (history of stroke, urinary incontinence, osteoarthritis, rheumatic disease, diabetes and Parkinson's disease) was checked by the specialised nurse, based on the patients' medical records and information from the treating physicians. An overview of the fall-related risk factors is presented in Table 2 for women who did or did not sustain a fall during the follow-up period.

\section{Depressive symptoms}

The Edinburgh Depression Scale (EDS) [26] was used to assess depressive symptoms at baseline. The EDS is a ten-item self-rating scale performed over a seven-day period with a four-point scale ranging from 0 to 3 (range 0-30). It was originally designed as the Edinburgh Postnatal Depression Scale (EPDS) for detecting postnatal depression in postpartum women [26]. The Dutch version of the EPDS has been validated showing appropriate psychometric characteristics [27]. The EPDS was later validated in a group of non-childbearing mothers, and middle-aged women, as well as in subjects aged over 55 years (men and women), and renamed the Edinburgh Depression Scale (EDS) [28-30]. The internal consistency of the EDS is good and its specificity and positive predictive value are appropriate [26-30]. Higher scores indicate the presence of more depressive symptoms. In the present study, depression was defined as an EDS score $>11$.

Table 1 Baseline characteristics of 181 women with a recent fracture who did or did not sustain a fall during the twoyear follow-up period

\begin{tabular}{|c|c|c|c|}
\hline Variable & & $\begin{array}{l}\text { Did not fall } \\
(n=102)\end{array}$ & $\begin{array}{l}\text { Fell } \\
(n=79)\end{array}$ \\
\hline \multicolumn{4}{|l|}{ Demographic characteristics } \\
\hline Age (mean, SD)* & & $67.98(5.73)$ & $70.05(6.70)$ \\
\hline \multirow[t]{2}{*}{ Marital status } & Married/living together & $70(69 \%)$ & $48(61 \%)$ \\
\hline & Single/divorced/widowed & $32(31 \%)$ & $31(39 \%)$ \\
\hline \multirow[t]{3}{*}{ Education } & Elementary school & $59(58 \%)$ & $40(51 \%)$ \\
\hline & Middle school/high school & $37(36 \%)$ & $33(42 \%)$ \\
\hline & College/University & $6(6 \%)$ & $6(8 \%)$ \\
\hline \multicolumn{4}{|l|}{ BMD measurements } \\
\hline BMD femoral neck (mean, SD) & & $0.68(0.11)$ & $0.66(0.11)$ \\
\hline BMD lumbar spine (mean, SD) & & $0.87(0.15)$ & $0.84(0.23)$ \\
\hline \multirow[t]{3}{*}{ WHO classification } & Osteoporosis & $48(47 \%)$ & $42(53 \%)$ \\
\hline & Osteopenia & $32(31 \%)$ & $26(33 \%)$ \\
\hline & Normal BMD & $22(22 \%)$ & $11(14 \%)$ \\
\hline \multirow[t]{4}{*}{ Type of fracture according to Center [22] } & Hip & $11(11 \%)$ & $8(10 \%)$ \\
\hline & Major & $24(24 \%)$ & $15(19 \%)$ \\
\hline & Minor & $55(54 \%)$ & $43(54 \%)$ \\
\hline & Fingers/toes & $12(12 \%)$ & $13(16 \%)$ \\
\hline
\end{tabular}


Table 2 The prevalence of fall-related risk factors at baseline in 181 women with a recent fracture who did or did not sustain a fall during the two-year follow-up period

\begin{tabular}{|c|c|c|}
\hline Variable & $\begin{array}{l}\text { Did not fall } \\
n=102(\%)\end{array}$ & $\begin{array}{l}\text { Fell } \\
n=79(\%)\end{array}$ \\
\hline Living on one's own & $31(30)$ & $29(37)$ \\
\hline$\geq 1$ fall during 12 months prior to inclusion & $77(75)$ & $66(84)$ \\
\hline Use of walking aid & $16(16)$ & $12(15)$ \\
\hline Comorbidity $^{\mathrm{a} *}$ & $47(46)$ & $55(70)$ \\
\hline Use of anti-depressants & $3(3)$ & $5(6)$ \\
\hline Use of sedatives & $8(8)$ & $14(18)$ \\
\hline Use of antihypertensives & $35(34)$ & $25(32)$ \\
\hline$\geq 2$ units of daily alcohol consumption & $22(22)$ & $19(24)$ \\
\hline Physical inactivity & $14(14)$ & $16(20)$ \\
\hline Depression according to the EDS ${ }^{\mathrm{b} *}$ & $10(10)$ & $22(28)$ \\
\hline
\end{tabular}

${ }^{*} p<.05$

a history of stroke, urinary incontinence, osteoarthritis, rheumatic disease, diabetes and Parkinson's disease

b score $>11$

\section{Statistical analyses}

In order to determine differences in baseline characteristics, including the presence of depression, between women who did or did not sustain a fall during the follow-up period, independent samples t-test and Chisquare tests were used. To explore the relationship between continuous variables, Pearson correlations were calculated (two-tailed). Unadjusted ORs $(p<0.05,95 \%$ $\mathrm{CI})$ were calculated using single logistic regression analyses, with falls as the dependent variable. Adjusted ORs were calculated using multiple logistic regression analysis, with presence or absence of falls during the twoyear follow-up period as the dependent variable, entering all risk factors into the regression analysis. Statistical analyses were performed using the IBM Statistical Package for the Social Sciences (IBM SPSS) version 18.0.

\section{Results}

\section{Baseline characteristics and falls during follow-up}

The mean age of the participating women was 69 years (range, 60-84) and the majority was either married or living together with a partner (65\%). During the twoyear follow-up period, $44 \%(n=79)$ of the women sustained at least one fall; in total there were 220 fall incidents in these 79 women (mean $=2.78$; SD $=2.58$ ). Women who sustained a fall during follow-up were significantly older than those who did not $(\mathrm{t}=2.19, p=$ 0.03 ; Table 1). As shown in Table 1, there was no significant difference in marital status, education, BMD of the femoral neck and the lumbar spine, WHO T-score classification, or type of fracture between the two groups.

Of the 79 women who sustained a fall during followup, $57(72 \%)$ fell at least once in the first year, and 43
(54\%) fell at least once during the second year. The number of women who sustained a first fall during the first year $(n=57)$ was significantly larger compared to that during the second year $(n=22)\left(X^{2}=18.72\right.$, $\mathrm{df}=1$, $p<.001)$. However, with regard to the total number of falls $(n=220)$, there was no significant difference between the 116 fall incidents (53\%) occurring in the first year of follow-up (57 women) and the 104 fall incidents $(47 \%)$ in the second year (43 women). Thirty-nine percent $(n=31)$ of the women who sustained a fall during follow-up fell once, $25 \%(n=20)$ fell twice, and $35 \%$ fell three or more times $(n=28)$.

\section{Depression and falls}

Eighteen percent $(n=32)$ of all women in this study, suffered from depression at baseline (EDS scores $>11$ ), $69 \%$ of the depressed women $(n=22)$ sustained a fall during follow-up. The proportion of women that suffered from depression at baseline and sustained a fall during follow-up (22 out of $79 ; 28 \%$ ) was significantly higher than the proportion of women with depression that did not sustain a fall during follow-up ((10 out of $102 ; 10 \%) ; X^{2}=8.76$, df $=1, p=.003$; Table 2). Depression at baseline was not related to the number of falls (once or more during the follow-up period) nor to the time of falling (first- and/or second-year, data not shown).

\section{Other fall-related risk factors}

The prevalence of co-morbidity at baseline was also significantly higher in women who sustained a fall during follow-up compared to those who did not $\left(X^{2}=9.10\right.$, $\mathrm{df}$ $=1, p=.003$; Table 2). With respect to the other fallrelated risk factors (living on one's one, $\geq 1$ fall during 12 months prior to inclusion, use of a walking aid, use of anti-depressants, use of sedatives, use of antihypertensives, $\geq 2$ units of daily alcohol consumption, and physical inactivity) no significant differences were found between women who sustained a fall during follow-up and women who did not.

\section{Correlations}

As showed in Table 3, significant correlations were found between age and femoral neck BMD, with a decrease in BMD with increasing age $(r=-.312, p=<$ .001 ), and femoral neck BMD and lumbar spine BMD with an increase in BMD of the lumbar spine with increasing BMD of the femoral neck $(r=.370, p=<$ $.001)$.

\section{Logistic regression analyses}

The results of single logistic regression analyses are shown in Table 4. Higher age $(\mathrm{OR}=1.06,95 \% \mathrm{CI}=$ $1.01-1.11)$, presence of co-morbidity $(\mathrm{OR}=2.68,95 \% \mathrm{CI}$ 
Table 3 Correlations between depression, age, BMD of the femoral neck and BMD of the lumbar spine

\begin{tabular}{lllll}
\hline Variable & Depressive symptoms & Age & BMD femoral neck & BMD lumbar spine \\
\hline Depressive symptoms & 1 & .129 & -.039 & .071 \\
Age & .129 & 1 & $-.312^{*}$ & -.070 \\
BMD femoral neck & -.039 & $-.312^{*}$ & 1 & $.370^{*}$ \\
BMD lumbar spine & .071 & -.070 &. $\mathbf{3 7 0 *}$ & 1 \\
\hline
\end{tabular}

${ }^{*} p<.001$

$=1.45-4.97)$, use of sedatives $(\mathrm{OR}=2.53,95 \% \mathrm{CI}=$ 1.01-6.38), and depression according to the EDS (OR = $3.55,95 \% \mathrm{CI}=1.57-8.04)$, were found to be significantly related to future falls. Multiple logistic regression showed that the presence of co-morbidity $(\mathrm{OR}=2.25$, 95\% CI $=1.11-4.56)$ and depression $(\mathrm{OR}=4.13,95 \% \mathrm{CI}$ $=1.58-10.80)$ at baseline were independently related to future falls (Table 5). According to logistic regression analyses, no other significant relations were found.

\section{Discussion}

This study shows that the presence of depression after a recent low-energy fracture was an independent risk factor for future falls during a two-year follow-up period in older post-menopausal women $(\mathrm{OR}=4.13,95 \% \mathrm{CI}=$ 1.58-10.80). Moreover, the existence of co-morbidity increased the risk of falls within two years $(\mathrm{OR}=2.25$, 95\% CI $=1.11-4.56)$.

Depression at baseline (EDS scores > 11) was present in $18 \%$ of the women, which is comparable to other studies carried out in the Netherlands. Beekman et al. [17] reported a prevalence of $17 \%$ in a general population of Dutch women aged over 60 years, while another Dutch primary care study reported a prevalence of $19 \%$ [18].

Table 4 Single logistic regression, dependent variable: sustaining future falls during the two-year follow-up period in 181 women with a recent low-energy fracture

\begin{tabular}{|c|c|c|}
\hline Variable at baseline & OR & $95 \% \mathrm{Cl}$ \\
\hline Age* $^{*}$ & 1.06 & $1.01-1.11$ \\
\hline Married/living together & 0.71 & $0.38-1.31$ \\
\hline BMD femoral neck hip & 0.17 & $0.01-2.89$ \\
\hline Living on one's own & 1.33 & $0.71-2.48$ \\
\hline History of falls during 12 months prior to inclusion & 1.65 & $0.78-3.48$ \\
\hline Use of walking aid & 0.96 & $0.43-2.17$ \\
\hline Comorbidity $^{a_{*}}$ & 2.68 & $1.45-4.97$ \\
\hline Use of anti-depressants & 2.23 & $0.52-9.63$ \\
\hline Use of sedatives* & 2.53 & $1.01-6.38$ \\
\hline Use of antihypertensives & 0.89 & $0.47-1.66$ \\
\hline$\geq 2$ units of daily alcohol consumption & 1.15 & $0.57-2.32$ \\
\hline Physical inactivity & 1.60 & $0.73-3.51$ \\
\hline Depression according to the $\mathrm{EDS}^{\mathrm{b}_{*}}$ & 3.55 & $1.57-8.04$ \\
\hline
\end{tabular}

* $p<.05$

${ }^{a}$ history of stroke, urinary incontinence, osteoarthritis, rheumatic disease, diabetes and Parkinson's disease

b score $>11$
The one-year incidence of falls among communitydwelling elderly has been estimated at $30 \%$, which is in accordance with our findings (31\%) [1]. The number of falls was equally distributed over the two-year follow-up period. However, $72 \%$ of the women who sustained a fall during follow-up, fell during the first year of followup, while $28 \%$ sustained their first fall in the second year. Therefore, the number of falls did not decline over time, but the incidence of women with a new, first fall did. This means that the women who sustained their first fall in the first year of follow-up had a high risk of falling during the second year. It has repeatedly been reported in the literature that a history of a previous fall is a particular risk factor for subsequent falls [2,15,31]. However, in the present study, the history of a fall during the 12 months prior to inclusion did not affect the risk of falling during the two-year follow-up period.

In addition, falls did occur significantly and independently more often in women who were depressed at baseline compared to non-depressed women. In a large sample of older women from the general population (with no recent history of low-energy fracture), Whooley et al. [16]

Table 5 Multiple logistic regression, dependent variable: sustaining future falls during the two-year follow-up period in 181 women with a recent low-energy fracture

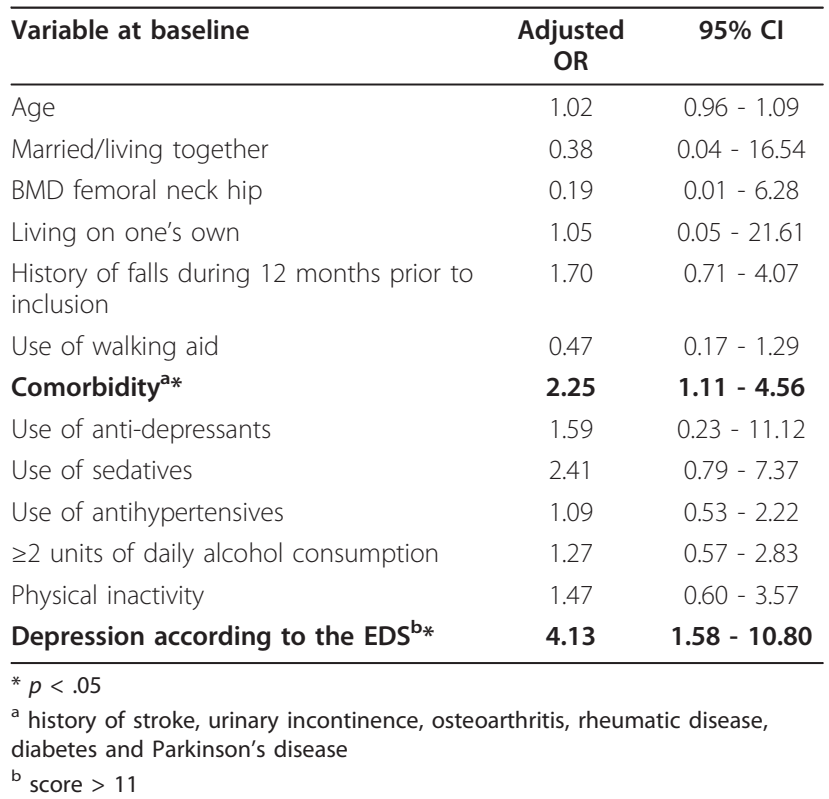


showed that depression and falls were independently related during two years of follow-up (OR 1.4). Stalenhoef et al. [15] showed that the risk for falling was about twice as high in depressed primary care patients (with no history of a recent low-energy fracture) compared to nondepressed subjects.

The presence of co-morbid conditions at baseline (e.g., osteoarthritis, diabetes, Parkinson's disease) was also significantly related to falls during the two-year follow-up. Most of these conditions interfere with normal balance and physical activity and are well known risk factors for falling [1].

Sustaining a fracture can have a major impact on daily life [32], which can result in depression. In turn, depression after a fracture has been shown to be a risk factor for delayed recovery $[19,20,33]$. Moreover, this study points out that depression is an important risk factor for future falls in women with a recent low-energy fracture, thereby substantially increasing the risk of subsequent fractures. BMD was not related to the incidence of falls. However, it has repeatedly been reported that fractures after falls are particularly common in patients with osteopenia [34,35].

The question why depression is related to falls remains to be answered. It has been shown that the use of anti-depressants and sedatives can lead to falls and hip fracture $[2,36,37]$. In our study, the use of sedatives was related to falls, only at a univariate level. Haagstra et al. [38] found that health-related quality of life decreased with the number of comorbid diseases in injured patients. It might be argued that the presence of comorbidity affects quality of life in older women with a recent fracture, making them more vulnerable for depression and in the same time more prone to falls through difficulties with walking and locomotion. More research is needed in explaining the relationship between depression and falls and the role of comorbidity.

Several limitations of the present study should be mentioned. Firstly, a bias could have occurred due to the high non-response rate or the use of subjects from only two hospitals from the same area. Depressed women may have been more willing to participate in our study than non-depressed women. Although we have no detailed data on the characteristics of the nonresponders, we do know that there were no significant differences between the demographic characteristics (which are important general determinants of depression) of our sample and those of the total population that visited the F\&O clinics. Moreover, the number of women with depression according to the EDS and the number of falls occurring in our study were similar to that of the general postmenopausal population, again suggesting no bias. Secondly, we did not assess depression at a syndromic level, which would usually be performed during a structural interview. During such an interview, there is also the opportunity to assess lifetime history of depression and/or chronic episodes of depression. It would be interesting to discover whether women with a previous history of depression are particularly at risk for another depressive episode after a low-energy fracture, and hence for the incidence of future falls. Thirdly, we assessed falls annually by means of detailed questionnaires and interviews, as opposed to using a diary. This may have led to an underestimation of the number of falls. A further limitation is that we did not include other known determinants of falls (e.g., vision disabilities, normal daily activities, dizziness).

\section{Conclusions}

In regular outpatient $\mathrm{F} \& \mathrm{O}$ clinics, most clinicians concentrate on the presence of skeletal-related risk factors for fractures (osteoporosis, family history of hip fracture, glucocorticoid use) rather than on risk factors associated with future falls. Depression is an important risk factor for future falls and is associated with delayed recovery. Based on the findings from the present study, we propose that clinicians who are treating patients with recent fractures should anticipate the presence of depression. Further research is needed to evaluate the effect of treatment and the prevention of depression after a recent fracture.

\section{Acknowledgements}

This research was supported by the Dutch Bone and Joint Decade and healthcare insurance companies CZ Tilburg (the Netherlands) and UVIT (Univé, VGZ, IZA, Trias) Nijmegen (the Netherlands). The design, execution, analysis, interpretation and writing-up of the data and writing were financially supported by PoZoB and Tilburg University.

\section{Author details}

${ }^{1}$ Tilburg University, CoRPS - Center of Research on Psychology in Somatic diseases, PO Box 90153, 5000 LE Tilburg, the Netherlands. ${ }^{2}$ Diagnostiek voor U, PO Box 2406, 5600 CK Eindhoven, the Netherlands. ${ }^{3}$ Stichting Severinus, PO Box 6666, 5500 MA Veldhoven, the Netherlands. ${ }^{4}$ PoZoB, Coordination Centre of Practice Nurses for South East Netherlands, PO Box 312, $5500 \mathrm{AH}$ Veldhoven, the Netherlands. ${ }^{5}$ VieCuri Medical Centre Noord-Limburg, Department of Internal Medicine, PO Box 1926, 5900 BX Venlo, the Netherlands. ${ }^{6}$ Maastricht University/Nutrim, Faculty of Health Medicine and Life Science, Department of Internal Medicine, PO Box 616, 6200 MD Maastricht, the Netherlands.

\section{Authors' contributions}

$\mathrm{MvdB}$ is the principle investigator and the main author of the manuscript. VJMP, JPWVdB and GLL are the supervisors of the principle investigator and responsible for the medical and scientific content of the manuscript. NAV, CJMW-vG and ACR have contributed substantially to the intellectual content of the manuscript. All authors have made substantially contributions to conception and design of the study and interpretation of the data or acquisition of data. Furthermore, all authors have been involved in drafting the manuscript or revising it critically for important intellectual content and read and approved the final manuscript and agree with publication of their names.

\section{Competing interests}

The authors declare that they have no competing interests. 
Received: 31 May 2011 Accepted: 7 November 2011

Published: 7 November 2011

\section{References}

1. Deandrea S, Lucenteforte E, Bravi F, Foschi R, La Vecchia C, Negri E: Risk factors for falls in community-dwelling older people: A systematic review and meta-analysis. Epidemiology 2010, 21:658-668.

2. Tromp AM, Pluijm SMF, Smit JH, Deeg DJH, Bouter LM, Lips P: Fall-risk screening test: A prospective study on predictors for falls in communitydwelling elderly. J Clin Epidemiol 2001, 54:837-844.

3. Stel VS, Smit JH, Pluijm SMF, Lips P: Consequences of falling in older men and women and risk factors for health service use and functional decline. Age Ageing 2004, 33:58-65.

4. Alexander BH, Rivara FP, Wolf ME: The cost and frequency of hospitalization for fall-related injuries in older adults. Am J Public Health 1992, 82:1020-1023.

5. World Health Organisation (WHO), D.o.l.a.V.P: Noncommunicable disease and mental health cluster, The injury Chart Book. Fall-related injuries Geneva, Switzerland: World Health Organisation; 2002.

6. Stevens JA, Corso PS, Finkelstein EA, Miller TR: The costs of fatal and nonfatal falls among older adults. Inj Prev 2006, 12:290-295.

7. Appleby PN, Allen NE, Roddam AW, Key TJ: Physical activity and fracture risk: A prospective study of 1898 incident fractures among 34,696 British men and women. J Bone Miner Metab 2008, 26:191-198.

8. Hartholt KA, van Beeck EF, Polinder S, van der Velde N, van Lieshout EM, Panneman MJ, van der Cammen TJ, Patka P: Societal consequences of falls in the older population: Injuries, healthcare costs, and long-term reduced quality of life. J Trauma 2011, 71:748-753.

9. Van Helden S, Wyers CE, Dagnelie PC, van Dongen MC, Willems G, Brink PRG, Geusens PP: Risk of falling in patients with a recent fracture. BMC Musculoskelet Disord 2007, 8:55.

10. Järvinen TLN, Sievänen H, Khan KM, Heinonen A, Kannus P: Shifting the focus in fracture prevention from osteoporosis to falls. BMJ 2008 , 336:124-126

11. Nguyen ND, Frost SA, Center JR, Eisman JA, Nguyen TV: Development of a nomogram for individualizing hip fracture risk in men and women. Osteoporos Int 2007, 18:1109-1117.

12. Nguyen ND, Frost SA, Center JR, Eisman JA, Nguyen TV: Development of prognostic nomograms for individualizing 5-year and 10-year fracture risks. Osteoporos Int 2008, 19:1431-1444.

13. Carpenter CR, Schaetzle MD, D'Antonio JA, Ricci PT, Coben JH: Identification of fall risk factors in older adult emergency department patients. Acad Emerg Med 2009, 16:211-219.

14. Kose N, Cuvalci S, Ekici G, Otman AS, Karakaya MG: The risk factors of fall and their correlation with balance, depression, cognitive impairment and mobility skills in elderly nursing home residents. Saudi Med J 2005, 26:978-981.

15. Stalenhoef PA, Diederiks JPM, Knottnerus JA, Kester ADM, Crebolder HFJM: $A$ risk model for the prediction of recurrent falls in community-dwelling elderly: A prospective cohort study. J Clin Epidemiol 2002, 55:1088-1094.

16. Whooley MA, Kip KE, Cauley JA, Ensrud KE, Nevitt MC, Browner WS, on behalf of the Study of Osteoporotic Fractures Research Group: Depression, falls, and risk of fracture in older women. Arch Intern Med 1999 159:484-490

17. Beekman ATF, Deeg DJH, van Tilburg T, Smit JH, Hooijer C, van Tilburg W: Major and minor depression in later life: A study of prevalence and risk factors. J Affect Disord 1995, 36:65-75.

18. Licht-Strunk E, van der Kooij KG, van Schaik DJF, van Marwijk HWJ, van Hout HPJ, de Haan M, Beekman ATF: Prevalence of depression in older patients consulting their general practitioner in The Netherlands. Int J Geriatr Psychiatry 2005, 20:1013-1019.

19. Feng L, Scherer SC, Tan BY, Chan G, Fong NP, Ng TP: Comorbid cognitive impairment and depression is a significant predictor of poor outcomes in hip fracture rehabilitation. Int Psychogeriatr 2010, 22:246-253.

20. Kempen Gl, Sanderman R, Scaf-Klomp W, Ormel J: The role of depressive symptoms in recovery from injuries to the extremities in older persons. A prospective study. Int J Geriatr Psychiatry 2003, 18:14-22.

21. Blonk MC, Erdtsieck RJ, Wernekinck MGA, Schoon EJ: The fracture and osteoporosis clinic: 1-year results and 3-month compliance. Bone 2007 40:1643-1649.
22. Center JR, Bliuc D, Nguyen TV, Eisman JA: Risk of subsequent fracture after low-trauma fracture in men and women. JAMA 2007, 297:387-394.

23. World Health Organization (WHO) Study Group: Assessment of fracture risk and its application to screening for postmenopausal osteoporosis. World Health Organ Tech Rep Ser 1994, 843:1-129.

24. Neyens JCL, Dijcks BPJ, de Kinkelder A, Graafmans WC, Schols JMGA: CBO guidelines to prevent accidental falls in the elderly: How can it be used in the institutionalized elderly? Tijdschr Gerontol Geriatr 2005, 36:155-160.

25. Emmelot-Vonk MH: Prevention of falls in the elderly-A key role for the falls clinic. Tijdsdchr Gerontol Geriatr 2005, 36:161-167.

26. Cox JL, Holden JM, Sagovsky R: Detection of postnatal depression Development of the 10-item Edinburgh postnatal depression scale. $\mathrm{Br} J$ Psychiatry 1987, 150:782-786.

27. Pop VJ, Komproe $H$, van Son MJ: Characteristics of the Edinburgh post natal Depression scale in The Netherlands. J Affect Disord 1992, 26:105-110.

28. Cox JL, Chapman G, Murray D, Jones P: Validation of the Edinburgh postnatal depression scale (EPDS) in non-postnatal women. J Affect Disord 1996, 39:185-189.

29. Becht MC, van Erp CF, Teeuwisse TM, van Heck GL, van Son MJ, Pop VJ: Measuring depression in women around menopausal age: Towards a validation of the Edinburgh depression scale. J Affect Disord 2001, 63:209-213.

30. Spek V, Nyklíček I, Cuijpers P, Pop V: Internet administration of the Edinburgh depression scale. J Affect Disord 2008, 106:301-305.

31. Nevitt MC, Cummings SR, Kidd S, Black D: Risk factors for recurrent nonsyncopal falls. A prospective study. JAMA 1989, 261:2663-2668.

32. Brenneman SK, Barrett-Connor E, Sajjan S, Markson LE, Siris ES: Impact of recent fracture on health-related quality of life in postmenopausal women. J Bone Miner Res 2006, 21:809-816.

33. Holmes J, House A: Psychiatric illness predicts poor outcome after surgery for hip fracture: A prospective cohort study. Psychol Med 2000 30:921-929.

34. Pasco JA, Seeman E, Henry MJ, Merriman EN, Nicholson GC, Kotowicz MA The population burden of fractures originates in women with osteopenia, not osteoporosis. Osteoporos Int 2006, 17:1404-1409.

35. Siris ES, Chen Y, Abbott TA, Barrett-Connor E, Miller PD, Wehren LE, Berger ML: Bone mineral density thresholds for pharmacological intervention to prevent fractures. Arch Intern Med 2004, 164:1108-1112.

36. Tinetti ME, Speechley M, Ginter SF: Risk factors for falls among elderly persons living in the community. N Engl J Med 1988, 319:1701-1707.

37. Liu B, Anderson G, Mittmann N, To T, Axcell T, Shear N: Use of selective serotonin-reuptake inhibitors or tricyclic antidepressants and risk of hip fractures in elderly people. Lancet 1998, 351:1303-1307.

38. Haagstra JA, van Beeck EF, Polinder S, Toet H, Panneman M, Bonsel GJ: The effect of comorbidity on health-related quality of life for injury patients in the first year following injury: comparison of three comorbidity adjustment approaches. Popul Health Metr 2011, 9:10.

\section{Pre-publication history}

The pre-publication history for this paper can be accessed here: http://www.biomedcentral.com/1471-2318/11/73/prepub

doi:10.1186/1471-2318-11-73

Cite this article as: van den Berg et al:: Depression after low-energy fracture in older women predicts future falls: a prospective observational study. BMC Geriatrics 2011 11:73. 